Landerer, ibber die Teichnann'schen Hämatin-Krystalle. 275

Procent abgebend, und etwa $3 / 4$ Pfund minder reinen Aethers, etwas Butteräther haltend, von nahe an 0,900 spec. Gewicht, an 1 Volum Wasser $20-25$, höchstens 30 Procent abgebend.

\title{
Ueber die Teichmann'schen Hämatin-Krystalle;
}

von

Dr. X. Landerer in Athen.

In der letzten Zeit wurde ich mit der Ausmittelung des Blutes auf einem Hemde von Seite des Gerichts beauftragt, und das gab mir Veranlassung, mich mit den Versuchen zur Darstellung der Teichmann'schen HämatinKrystalle zu beschäftigen. Wird der mit dem Blute beschmutzte Gegenstand, sei es Holz, Eisen, ja ein Stein oder ein Stückchen abgekratzter Mauer mit einigen Tropfen concentrirter Essigsäure gekocht, mit oder ohne $\mathrm{Zu}$ satz von Chlornatrium, und diese Lösung auf ein Glasplättchen gebracht und verdunstet, so zeigen sich unter dem Mikroskope die wundervollsten Krystall-Gestalten, die nebst andern Beweisen für die Gegenwart des Blutes immer den vorzüglichsten Beweis bilden können, so dass man diesen schönen Versuch niemals unterlassen darf. Ich stellte Versuche mit eingetrocknetem Hasenblut, mit Blut der Wanzen, mit dem der Schnecken an und erhielt in allen den angegebenen Fällen diese schönen Teichmann'schen Hämatin-Krystalle. Jeder, der sich mit solchen Versuchen zu beschäftigen Gelegenheit hat, muss dem Entdecker, dem Dr. Teichmann in Göttingen, zum besten Danke verbunden bleiben, den ich Demselben durch diese Zeilen auszudrücken beabsichtige.

Den vorstehenden Bemerkungen über die Bildung der Teichmann'schen Blutkrystalle, erlaube ich mir nun noch einige Bemerkungen hinzuzufügen, die ich zu berücksichtigen bitte, und sehe mit Vergnügen einer Gegenmittheilung entgegen. 
276 Landerer, über die Teichmann'schen Hämatin-Krystalle.

Ein Zufall wollte es, dass ich mich mit der Ausmittelung von Blutflecken auf einem Messer beschäftigen musste, das ein Mörder benutzt, um den Leichnam seines ermordeten Herrn in Stücke zu zerschneiden, um dieselben in einen Sack zu fuillen und fortschleppen zu können. Die Ermittelung, dass der auf dem Messer sich beiindende Flecken von Blut herrührte, hielt nicht schwer. Was nun die Bildung der Teichmann'schen Blutkrystalle anbetrifft, so fand ich es zweckdienlich, sich keines $\mathrm{Zu}$ satzes von Kochsalz zur Essigsäure zu bedienen, um nicht dadurch irre geführt zu werden. Wird reine Essigsäure mit Kochsalz gekocht, ohne Zusatz eines andern Stoffes, diese Lösung auf die angegebene Weise zur Trockne verdampft und unter das Mikroskop gebracht, so kommen Krystalle zum Vorschein, die mit den Teichmann'schen Blutkrystallen die grösste Aehnlichkeit haben, und Anlass geben können, sie dafür zu halten, die sich zeigenden Kryställchen sind theils Rhomboëder, theils federähnlichen Formen, die wahrscheinlich dem essigsauren Natron, das sich durch das Kochen der Kochsalzlösung mit der Essigsäure gebildet hat, angehören. Dies schliesse ich aus Folgendem: Wird verdünnte essigsaure Natronlösung unter das Mikroskop auf das Objectivglas gebracht und betrachtet, so bilden sich aus derselben ganz ähnliche Krystalle, wie die Teichmann'schen Blutkryställchen. Dem zufolge glaube ich es vortheilhaft, um jedem Irrthum zu entgehen, den vermeintlichen Bluttropfenfleck nur mit concentrirter Essigsäure auszukochen, die Lösung zu filtriren, im Falle es möglich ist, und diese Flüssigkeit bei gelinder Wärme abgedampft den mikroskopischen Untersuchungen zu unterwerfen. 